\title{
Neck circumference and early stage atherosclerosis: the cardiometabolic risk in Chinese (CRC) study
}

\author{
Jun Liang ${ }^{1 * \dagger}$, Yu Wang ${ }^{2+}$, Hongyan $\mathrm{Li}^{2}$, Xuekui Liu', Qinqin Qiü ${ }^{1}$ and Lu Qi $i^{3,4^{*}}$
}

\begin{abstract}
Background: Neck circumference (NC) has been previously related to cardiometabolic risk factors. In this study we examined the association between NC and early stage atherosclerosis in Chinese adults.

Methods: The study samples were from a community-based health examination survey in central China. In total 2,318 men and women (18-64 y) were included in the final analyses. Carotid radial pulse wave velocity (crPWV), carotid femoral PWV (cFPW), carotid artery dorsalis pedis PWV (cdPWV) and NC were measured.

Results: After adjustment for age, sex, lipids, glucose, blood pressure, heart rate, body mass index (BMI), high NC was significantly associated with an increasing trend of cfPWV, cdPWV and crPWV (P = 0.001, 0.049, and 0.038; respectively). In addition, we found significant interaction between hypertension status and $\mathrm{NC}$ level in relation to cfPWW, adjusted for age, sex, BMl, fasting glucose, lipids and heart rate $(P$ for interaction $=0.034)$. The associations between NC and cfPWV were significant $(P=0.02)$ among those with hypertension, but not significant among those without hypertension.
\end{abstract}

Conclusions: Our data showed that high NC was associated with an increased risk of early stage atherosclerosis in Chinese adults, independent of other metabolic risk factors. Hypertension might modify the association between NC and CFPW.

Keywords: Neck circumference, Early stage atherosclerosis, Pulse wave velocity

\section{Background}

Neck circumference (NC) was recently associated with various cardiovascular risk factors such as insulin resistance and biochemical components of metabolic syndrome such as fasting glucose, fasting triglycerides, and blood pressure, independent of body mass index (BMI) and waist circumference [1-4]. However, few studies have assessed the relation between NC and early stage atherosclerosis in Chinese adults [5].

Aortic stiffness is an established marker for early stage atherosclerosis. The recent European Society of

\footnotetext{
*Correspondence: mwlj521@163.com; nhlqi@channing.harvard.edu ${ }^{\dagger}$ Equal contributors

'Department of Endocrinology, Xuzhou Central Hospital, Xuzhou Clinical School of Xuzhou Medical College, Xuzhou Institute of Medical Sciences, Xuzhou Institute of Diabetes, Affiliated Hospital of Southeast University, 199\# South Jiefang Road, Xuzhou, Jiangsu 221009, China

${ }^{3}$ Department of Nutrition, Harvard School of Public Health, 665 Huntington Ave, Boston 02115, Massachusetts

Full list of author information is available at the end of the article
}

Hypertension/European Society of Cardiology guidelines for management of arterial hypertension suggested measurement of pulse wave velocity (PWV) as a tool for assessment of subclinical atherosclerosis [6]. PWV is a gold standard for assessing arterial stiffness, and has been widely used as an indicator for early-staged atherosclerosis [7-10]. PWV measured at different sites may reflect the atherosclerotic alterations at central (e.g. carotid femoral pulse wave velocity (cfPWV)) or peripheral arteries (e.g. carotid artery dorsalis pedis pulse wave velocity (cdPWV) and carotid radial pulse wave velocity (crPWV)). cfPWV is recognized as the "gold standard" parameter for the evaluation of arterial stiffness and has had a wide biomedical application $[11,12]$. The analysis of the peripheral pulse wave (cdPWV and crPWV) can provide parameters with different meanings in the arterial dynamics, some already used to assess the arterial stiffness $[13,14]$. 
The present study aimed to comprehensively investigate the relationship between NC and PWV measures for peripheral and central arterial stiffness in a large Chinese population.

\section{Methods \\ Study population}

In the cardiometabolic risk in Chinese (CRC) study, we performed a community-based health examination survey for 6,431 individuals (18-93y) who were randomly selected from residents living in the urban area of Xuzhou, China, in 2009. The details of this study have been presented elsewhere [3,15-18]. All subjects underwent a complete medical examination, a clinical consultation, and blood laboratory tests. All individuals provided details of their demographic, medical history, and use of medication at the time of their clinical consultation. We excluded people who did not undergo PWV determination or omitted blood sampling, and subjects with goiter and other neck masses and deformity. In total, 2,318 subjects were included in the final analyses. There was no significant difference in the clinical characteristics between the participants of the present analysis and those who were not included. The protocol and informed consent document were approved by the ethics committee of the Central Hospital of Xuzhou. All patients gave written informed consent.

\section{Anthropometric measures}

Neck Circumference $(\mathrm{cm})$ was measured with head erect and eyes facing forward, horizontally at the upper margin of the laryngeal prominence with a flexible tape. Body weight was measured in light clothing to the nearest $0.1 \mathrm{~kg}$ and height to the nearest $0.5 \mathrm{~cm}$. Height and body weight were measured with participants standing without shoes and heavy outer garments. Waist circumference was measured at the minimum abdominal girth to the nearest $0.1 \mathrm{~cm}$. BMI was calculated as weight (in kilograms) divided by height (in meters) squared. Blood pressure (BP) was measured after the subject had rested for at least 5 minutes with a mercury manometer by doctors. Three measurements, 60 seconds apart, were taken. The mean of the three measurements was used for analysis. Hypertension was defined as SBP $\geq 140 \mathrm{mmHg}$ and $\mathrm{DBP} \geq 90 \mathrm{mmHg}$, or the use of antihypertensive medication, according to the seventh report of the Joint National Committee on Prevention, Detection, Evaluation and Treatment of High Blood Pressure (JNC-7).

\section{Assessment of biomarkers}

Venous blood sample was drawn from all subjects after an overnight fast $(10 \mathrm{~h})$. The blood was transferred into glass tubes and allowed to clot at room temperature. Immediately following clotting serum was separated by centrifugation for $15 \mathrm{~min}$ at 3,000 rpm. Blood samples were drawn at 120 minutes after the glucose or carbohydrate load. Plasma glucose was measured using the hexokinase glucose-6-phosphate dehydrogenase method (Type 7600; Hitachi Ltd, Tokyo, Japan). The levels of total cholesterol(TC), triglyceride(TG), high-density lipoprotein cholesterol(HDL-C), low-density lipoprotein cholesterol(LDL-C) were determined enzymatically using an autoanalyzer (Type 7600; Hitachi Ltd., Tokyo, Japan). Fasting insulin was measured by a radioimmunoassay ethod (Pharmacia, Uppsala, Sweden). HbA1c was measured using high performance liquid chromatography (HPLC; HLC-723G7 hemoglobin HPLC ana-lyzer, Tosoh Corp.) according to the standardized method. The 1999 World Health Organization diagnostic criteria were used to diagnose diabetes. Individuals diagnosed by a physician and on antidiabetic medications (self-reported) and/or those who had fasting glucose $\geq 126 \mathrm{mg} / \mathrm{dl}(\geq 7 \mathrm{mmol} / \mathrm{L})$ and/or 2-hr post-glucose value $\geq 199.8 \mathrm{mg} / \mathrm{dl}(\geq 11.1 \mathrm{mmol} / \mathrm{L})$. National Cholesterol Education Programme (NCEP) guidelines were used for definition of dyslipidemia as follows [19]: Hypercholesterolemia: serum cholesterol levels $\geq 200 \mathrm{mg} / \mathrm{dl}$ ( $\geq 5.2 \mathrm{mmol} / \mathrm{l})$. Hypertriglyceridemia: serum TG levels $\geq 150 \mathrm{mg} / \mathrm{dl}(\geq 1.7 \mathrm{mmol} / \mathrm{l})$. Low HDL cholesterol: HDL cholesterol levels $<40 \mathrm{mg} / \mathrm{dl}(<1.04 \mathrm{mmol} / \mathrm{l})$ for men and $<50 \mathrm{mg} / \mathrm{dl}(<1.3 \mathrm{mmol} / \mathrm{l})$ for women. High LDL cholesterol: LDL cholesterol levels $\geq 130 \mathrm{mg} / \mathrm{dl}$ $(\geq 3.4 \mathrm{mmol} / \mathrm{l})$.

\section{Assessment of PWVs}

Before the study started, sonographers were trained for PWV measurements. All measurements were performed in a quiet room with controlled ambient temperature. The cfPWV was measured in the supine position after 5 min of bed rest using an automatic waveform analyzer (Complior System, Artech-Medical corp. French), the pulse wave of the carotid and femoral arteries was analyzed, estimating the delay with respect to the ECG wave and calculating the PWV. cdPWV and crPWV were obtained in a similar way, with the pulse wave being measured simultaneously in the right radial, dorsum of foot and right carotid arteries. 16 consecutive electrocardiogram gated waveforms were obtained and removed the three maximum and three minimum. We averaged 10 waveforms. PWV was based on the distance/time ratio (meters/second), was calculated as the path length divided by the transit time and expressed as $\mathrm{m} / \mathrm{s}$ [13]. The operators' concordance in pulse wave measurements ranged from 0.85 to 0.92 .

\section{Statistical analyses}

The relations between NC levels (in quintiles) and PWVs were examined using general linear regression models, adjusting for covariates including age, sex, BMI, heart 
rate(HR), fasting glucose, lipid profiles and BP. The interactions between $\mathrm{NC}$ and other cardiometabolic risk factors were assessed by introduction of cross-product term in the regression models. All the reported $\mathrm{P}$ values are two tailed. Variables with $P$ values of $<0.05$ were considered statistically significant. Data management and statistical analysis were conducted using SAS statistical software (version 9.1; SAS Institute, Inc., Cary, NC, USA).

\section{Results}

The study population was represented by $65.3 \%$ of men, with average age of 46.5 years. Table 1 shows the characteristics of the study participants according to NC levels (in quintiles). BMI, waist circumference, BP, and plasma levels of glucose, TC, TG and LDL-C showed significant differences across NC groups.

Table 2 displays the associations between PWVs and NC. After adjustment for age and sex, high levels of NC were significantly associated with an increasing trend of cfPWV, crPWV and cdPWV in a dose-dependent pattern. Further adjustment for lipids, glucose, systolic blood pressure (SBP), diastolic blood pressure (DBP), HR, and BMI did not significantly change the associations.

Then we examined whether cardiometabolic risk factors modified the relation between NC and cfPWVs (Table 3). Age, sex, BMI, HR, diabetes status, and dyslipidemia did not significantly interact with $\mathrm{NC}$ in relation to cfPWV.
We found significant interaction between hypertension status and NC level in relation to cfPWV, adjusted for age, sex, BMI, fasting glucose, lipids and HR (P for interaction $=0.034$ ). The associations between NC and cfPWV were significant $(P=0.02)$ among the participants with hypertension, but not among those with non-hypertension (Figure 1).

\section{Discussion}

In this study, we found that high NC was significantly associated increasing PWV measures for both peripheral and central arterial stiffness in Chinese adults. The associations were independent of other adiposity measures such as BMI and waist circumference, as well as traditional cardiometabolic risk factors. Moreover, we found that blood pressure modified the relation between $\mathrm{NC}$ and cfPWV.

As a risk factor for cardiovascular disease [20], aortic stiffness is recognized as an important marker for early artherosclerosis $[21,22]$. cfPWV is considered to be the gold standard method for assessing aortic stiffness [23,24], and has been associated with cardiovascular outcomes such as myocardial infarction, heart failure, and mortality $[7,25]$. Individual metabolic syndrome components have been related with subclinical atherosclerosis in previous studies, for example, central obesity showed strong correlation with carotid atherosclerosis [26-29]. Our findings

Table 1 Characteristics of participants by NC in quintiles

\begin{tabular}{|c|c|c|c|c|c|c|}
\hline \multirow[t]{2}{*}{ Variables } & \multicolumn{5}{|l|}{ NC (in quintiles) } & \multirow[b]{2}{*}{$\begin{array}{l}P \text { for } \\
\text { trend }\end{array}$} \\
\hline & $\begin{array}{l}\text { Q1 (women < 31, } \\
\text { men }<36 \text { ) }\end{array}$ & $\begin{array}{l}\text { Q2 (women 31-32, } \\
\text { men 36-37) }\end{array}$ & $\begin{array}{l}\text { Q3 (women 32.1-33, } \\
\text { men 37.1-38) }\end{array}$ & $\begin{array}{l}\text { Q4 (women 33.1-34, } \\
\text { men 38.1-40) }\end{array}$ & $\begin{array}{l}\text { Q5 (women > 34.1, } \\
\text { men > 40) }\end{array}$ & \\
\hline $\mathrm{N}$ & 670 & 393 & 381 & 494 & 380 & \\
\hline Age, years & $46.4 \pm 10.1$ & $43.6 \pm 9.1$ & $45.8 \pm 9.5$ & $46.9 \pm 9.4$ & $46.8 \pm 8.8$ & 0.498 \\
\hline $\mathrm{BMI}, \mathrm{kg} / \mathrm{m}^{2}$ & $22.5 \pm 2.4$ & $24.0 \pm 2.2$ & $25.0 \pm 2.2$ & $26.1 \pm 2.3$ & $27.9 \pm 3.0$ & $<0.0001$ \\
\hline WC, $\mathrm{cm}$ & $80.4 \pm 7.7$ & $84.6 \pm 7.1$ & $87.6 \pm 7.7$ & $91.7 \pm 7.2$ & $96.1 \pm 9.0$ & $<0.0001$ \\
\hline Systolic blood pressure, mmHg & $121.1 \pm 15.2$ & $124.4 \pm 15.2$ & $124.2 \pm 15.8$ & $128.3 \pm 16.3$ & $130.7 \pm 15.6$ & $<0.0001$ \\
\hline Diastolic blood pressure, mmHg & $77.1 \pm 11.1$ & $77.9 \pm 10.7$ & $80.0 \pm 11.4$ & $82.6 \pm 11.6$ & $83.9 \pm 11.4$ & $<0.0001$ \\
\hline Fasting glucose, mmol/L & $5.2 \pm 1.5$ & $5.1 \pm 0.9$ & $5.3 \pm 1.1$ & $5.3 \pm 1.1$ & $5.5 \pm 1.4$ & 0.001 \\
\hline Totalcholesterol, mmol/l & $4.9 \pm 0.9$ & $5.1 \pm 0.9$ & $5.1 \pm 0.9$ & $5.1 \pm 0.9$ & $5.2 \pm 1.0$ & 0.0001 \\
\hline Triglyceride, mmol/L & $1.4 \pm 1.2$ & $1.8 \pm 1.9$ & $1.8 \pm 1.5$ & $2.1 \pm 1.7$ & $2.3 \pm 2.6$ & $<0.0001$ \\
\hline LDL-C, mmol/L & $2.9 \pm 0.8$ & $3.0 \pm 0.8$ & $3.0 \pm 0.8$ & $3.1 \pm 0.8$ & $3.1 \pm 0.8$ & $<0.0001$ \\
\hline HDL-C, mmol/L & $1.3 \pm 0.3$ & $1.3 \pm 0.3$ & $1.2 \pm 0.3$ & $1.1 \pm 0.3$ & $1.1 \pm 0.3$ & 0.0037 \\
\hline Hypertention & $19.7 \%$ & $20.1 \%$ & $22.8 \%$ & $27.7 \%$ & $31.8 \%$ & $<0.0001$ \\
\hline Diabetes & $6.1 \%$ & $7.6 \%$ & $10.0 \%$ & $10.9 \%$ & $12.6 \%$ & 0.0062 \\
\hline High LDL & $11.2 \%$ & $12.0 \%$ & $13.9 \%$ & $18.6 \%$ & $18.9 \%$ & $<0.0001$ \\
\hline Low HDL & $4.2 \%$ & $4.8 \%$ & $5.5 \%$ & $5.9 \%$ & $6.3 \%$ & 0.0159 \\
\hline Hypertriglyceridemia & $9.9 \%$ & $11.2 \%$ & $12.1 \%$ & $15.8 \%$ & $17.9 \%$ & $<0.0001$ \\
\hline Hypercholesterolemia & $10.9 \%$ & $12.7 \%$ & $13.4 \%$ & $17.6 \%$ & $18.8 \%$ & 0.0317 \\
\hline
\end{tabular}

Abbreviations: WC waist circumference, HDL-C high density lipoprotein cholesterol, LDL-C low-density lipoprotein cholesterol. Data are age and sex adjusted; Mean \pm standard deviation; Linear regression model was used to test trend for continuous variables. 
Table 2 Associations of NC with central and peripheral arterial stiffness

\begin{tabular}{|c|c|c|c|c|c|c|}
\hline & \multicolumn{6}{|c|}{ NC (in quintiles) } \\
\hline & Q1 & Q2 & Q3 & Q4 & Q5 & $P$ for trend \\
\hline cfpwV & $10.65(1.84)$ & $10.69(1.75)$ & $10.62(1.83)$ & $10.99(2.00)$ & $11.01(1.78)$ & 0.001 \\
\hline cfpwv & $9.62(1.47)$ & $9.67(1.53)$ & $9.75(1.53)$ & $9.96(1.40)$ & $10.02(1.51)$ & 0.049 \\
\hline cfpwv & $10.44(1.53)$ & $10.41(1.43)$ & $10.55(1.62)$ & $10.67(1.55)$ & $10.61(1.50)$ & 0.038 \\
\hline
\end{tabular}

PWVs are presented as mean (standard deviation), adjusted sex, age, TC, TG, HDL, LDL, glucose, SBP, DBP, HR, BMI.

are consistent with several previous studies. Fitch et al. [30] found significant association between NC and carotid intima thickness. Zhou et al. [31] found that NC was significantly associated with cardiometabolic risk factors independent of the classical anthropometric indices in adults Chinese.
The precise mechanisms underlying the associations between NC and arterial stiffening remain not fully understood. In our study, adjustment for various cardiometabolic risk factors, such as age, sex, BMI, fasting glucose, lipids, BP and HR, did not change the associations between $\mathrm{NC}$ and PWVs, suggesting that the effects of $\mathrm{NC}$

Table 3 Stratified associations between NC and cfPWV by cardiometabolic risk factors

\begin{tabular}{|c|c|c|c|c|c|c|c|}
\hline & Q1 & Q2 & Q3 & Q4 & Q5 & $p$ for trend & $p$ for interaction \\
\hline \multicolumn{8}{|l|}{ Sex } \\
\hline 0 & $9.87 \pm 1.40$ & $10.07 \pm 1.79$ & $9.89 \pm 1.25$ & $10.46 \pm 1.93$ & $10.38 \pm 1.50$ & 0.024 & 0.387 \\
\hline 1 & $10.90 \pm 1.89$ & $10.94 \pm 1.67$ & $10.91 \pm 1.94$ & $11.09 \pm 2.00$ & $11.28 \pm 1.83$ & 0.003 & \\
\hline \multicolumn{8}{|l|}{ Age } \\
\hline$<40$ & $9.96 \pm 1.28$ & $10.23 \pm 1.29$ & $10.26 \pm 1.37$ & $10.30 \pm 1.33$ & $10.49 \pm 1.28$ & 0.009 & 0.506 \\
\hline 40 to 60 & $10.45 \pm 1.33$ & $10.28 \pm 1.33$ & $10.27 \pm 1.29$ & $10.72 \pm 1.42$ & $10.76 \pm 1.49$ & 0.048 & \\
\hline$>60$ & $11.59 \pm 2.39$ & $11.61 \pm 2.15$ & $11.43 \pm 2.45$ & $11.83 \pm 2.59$ & $11.61 \pm 2.14$ & 0.183 & \\
\hline \multicolumn{8}{|l|}{ BMI } \\
\hline$<28$ & $10.65 \pm 1.84$ & $10.69 \pm 1.76$ & $10.62 \pm 1.84$ & $11.00 \pm 2.06$ & $10.85 \pm 1.57$ & 0.034 & 0.230 \\
\hline$>=28$ & $10.39 \pm 1.86$ & $10.78 \pm 1.47$ & $10.74 \pm 1.74$ & $10.99 \pm 1.73$ & $11.18 \pm 1.96$ & 0.211 & \\
\hline \multicolumn{8}{|l|}{$\mathrm{HR}$} \\
\hline$<=65$ & $10.36 \pm 1.56$ & $10.28 \pm 1.46$ & $10.28 \pm 1.26$ & $10.70 \pm 1.66$ & $10.56 \pm 1.35$ & 0.030 & 0.868 \\
\hline$>65,<=75$ & $10.59 \pm 1.83$ & $10.69 \pm 1.83$ & $10.50 \pm 1.81$ & $11.02 \pm 1.90$ & $10.99 \pm 1.65$ & 0.008 & \\
\hline$>75$ & $11.12 \pm 2.11$ & $11.15 \pm 1.85$ & $11.13 \pm 2.23$ & $11.33 \pm 2.40$ & $11.40 \pm 2.09$ & 0.202 & \\
\hline \multicolumn{8}{|l|}{ Diabetes } \\
\hline No & $10.52 \pm 1.70$ & $10.59 \pm 1.70$ & $10.44 \pm 1.57$ & $10.81 \pm 1.75$ & $10.87 \pm 1.68$ & 0.131 & 0.316 \\
\hline Yes & $12.25 \pm 2.63$ & $12.13 \pm 1.83$ & $12.31 \pm 2.85$ & $12.47 \pm 3.05$ & $11.95 \pm 2.17$ & 0.282 & \\
\hline \multicolumn{8}{|c|}{ Hypercholesterolemia } \\
\hline No & $10.42 \pm 1.80$ & $10.47 \pm 1.60$ & $10.54 \pm 1.87$ & $10.80 \pm 1.89$ & $10.90 \pm 1.74$ & 0.018 & 0.982 \\
\hline Yes & $10.83 \pm 1.89$ & $10.88 \pm 1.87$ & $11.08 \pm 1.75$ & $11.16 \pm 2.11$ & $11.23 \pm 1.82$ & 0.010 & \\
\hline \multicolumn{8}{|c|}{ Hypertriglyceridemia } \\
\hline No & $10.51 \pm 1.82$ & $10.56 \pm 1.86$ & $10.70 \pm 1.89$ & $10.87 \pm 2.04$ & $10.91 \pm 1.62$ & 0.013 & 0.996 \\
\hline Yes & $10.98 \pm 1.87$ & $11.03 \pm 1.41$ & $11.08 \pm 1.64$ & $11.13 \pm 1.95$ & $11.31 \pm 1.89$ & 0.017 & \\
\hline \multicolumn{8}{|l|}{ High LDL } \\
\hline No & $10.51 \pm 1.78$ & $10.58 \pm 1.63$ & $10.61 \pm 1.96$ & $10.93 \pm 1.95$ & $11.00 \pm 1.83$ & 0.021 & 0.890 \\
\hline Yes & $10.66 \pm 2.01$ & $10.83 \pm 1.94$ & $11.01 \pm 1.49$ & $11.06 \pm 2.08$ & $11.14 \pm 1.70$ & 0.006 & \\
\hline \multicolumn{8}{|l|}{ Low HDL } \\
\hline No & $10.70 \pm 1.83$ & $10.81 \pm 1.89$ & $10.53 \pm 1.95$ & $11.03 \pm 2.18$ & $10.97 \pm 1.86$ & 0.113 & 0.074 \\
\hline Yes & $10.47 \pm 1.85$ & $10.53 \pm 1.34$ & $10.76 \pm 1.63$ & $10.95 \pm 1.72$ & $11.06 \pm 1.70$ & $<0.001$ & \\
\hline
\end{tabular}

Analyses were adjusted for age, sex, BMl, glucose, total cholesterol, triglyceride, HDL-C, LDL-C, blood pressure, heart rate, diabetes, dyslipidemia but not the strata variable. cfPWV is presented as mean \pm standard deviation. 


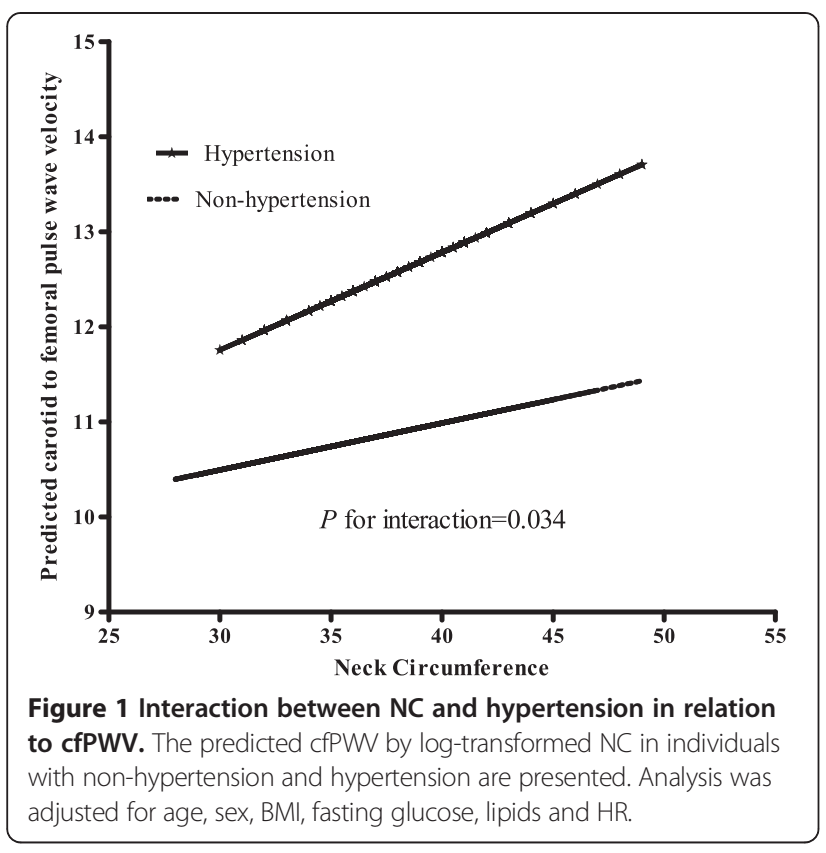

are less likely to be mediated by these factors. Various mechanisms have been proposed to link NC with development of atherosclerosis. Upper-body subcutaneous fat has been demonstrated to be responsible for the majority of systemic free fatty acid release, particularly in obese individuals [32]. It has been shown that elevated concentration of free fatty acid increased oxidative stress [33] and provoked vascular endothelial injury [34]. In addition, $\mathrm{NC}$ is an important predictor for obstructive sleep apnea (OSA), and OSA has been associated with arterial stiffening $[35,36]$.

Intriguingly, we found that the adverse effects of NC on central arterial stiffness appeared to be more evident in people with hypertension than those with normal blood pressure. Notably, on average cfPWV was much higher and its variance was larger in individuals with hypertension than those without hypertension (Figure 1); it is therefore not surprising a null association was observed between NC and cfPWV in subjects without hypertension because of the narrow variance. Laakso [37] reported that a higher NC was associated with about 3-fold increased risk of hypertension after adjustment for BMI. However, our data indicate that the associations between $\mathrm{NC}$ and cfPWV were independent of blood pressure, suggesting other mechanisms might be involved to explain the stronger associations in patients with hypertension. High NC has been related to various metabolic changes. We assume that certain changes may interact with hypertension in promoting atherosclerosis. For example, in a previous prospective study, it was found that inflammation-mediated proatherogenic activation led to significant increase of arterial stiffness in essential hypertensive patients [38]. Our findings suggest that high NC levels may play a more important role in arterial stiffness along with hypertension. This finding might have important clinical implications for prevention and intervention of cardiovascular risk at early stage. Further investigations are warranted to explore the potential mechanisms.

To our knowledge, the present study is among the first to assess the associations of $\mathrm{NC}$ and markers of early stage atherosclerosis in apparently healthy Chinese adults. However, several limitations of this study warrant consideration. First, the study is cross-sectional, thus we could not define a causal association between NC and PWVs. Second, neck circumference is used to represent upperbody subcutaneous fat, we did not perform radiographic measures to quantify this depot of fat directly. Potential confounding might exist as risk factors such as cigarette smoking was not measured in our study. Intima-Media Thickness and ankle-brachial-index are complementary parameters to evaluate the severity of early atherosclerosis $[39,40]$. However these markers were not measured in our study. Finally, the study was performed in a Chinese population, further studies in other populations of different ethnicities are warranted to verify our findings.

\section{Conclusions}

In summary, we found that high $\mathrm{NC}$ was associated with markers of an increased risk of early stage atherosclerosis in Chinese adults, independent of other metabolic risk factors. Blood pressure might modify the associations.

\section{Abbreviations}

NC: Neck circumference; PWV: Pulse wave velocity; cfPWV: carotid femoral PWV; cdPW: carotid artery dorsalis pedis; $\mathrm{CrPWV}$ : carotid radial pulse wave velocity; CRC: Cardiometabolic Risk in Chinese; BMI: Body Mass Index; BP: Blood pressure; TC: Cholesterol; TG: Triglyceride; HDL-C: High-density lipoprotein cholesterol; LDL-C: Low-density lipoprotein cholesterol; HR: Heart rate; SBP: Systolic blood pressure; DBP: Diastolic blood pressure; OSA: Obstructive sleep apnea.

\section{Competing interests}

The authors declare that they have no competing interests.

\section{Authors' contributions}

Conceived and designed the experiments: JL LQ. Performed the experiments: YW JL QQ LQ. Analyzed the data: $J L$ XL LQ. Contributed reagents/materials/analysis tools: JL LQ. Wrote the manuscript: JL LQ. Overall responsibility: JL LQ. All authors read and approved the final manuscript.

\section{Acknowledgements}

We are grateful to Ping Zeng (Xuzhou Medical College, Xuzhou, Jiangsu, China) for assistance with related statistical analyses.

\section{Grant support}

Dr. Qi's research is supported by NIH grants DK091718, HL071981, the American Heart Association Scientist Development Award, and the Boston Obesity Nutrition Research Center (DK46200). Dr. Jun Liang's research was sponsored by Jiangsu Provincial Bureau of Health Foundation (H201356) \& International Exchange Program and Jiangsu Six Talent Peaks Program (2013-WSN-013), It was also supported by the Xuzhou Outstanding Medical Academic Leader project and a Xuzhou Science and Technology Grant (XM13B066, XZZD1242). We thank all subjects for participating in this study. 


\section{Author details}

${ }^{1}$ Department of Endocrinology, Xuzhou Central Hospital, Xuzhou Clinical School of Xuzhou Medical College, Xuzhou Institute of Medical Sciences, Xuzhou Institute of Diabetes, Affiliated Hospital of Southeast University, 199\# South Jiefang Road, Xuzhou, Jiangsu 221009, China. ${ }^{2}$ Xuzhou Medical College, Xuzhou, Jiangsu 221009, China. ${ }^{3}$ Department of Nutrition, Harvard School of Public Health, 665 Huntington Ave, Boston 02115, Massachusetts. ${ }^{4}$ Channing Laboratory, Department of Medicine, Brigham and Women's Hospital and Harvard Medical School, Boston, Massachusetts.

Received: 17 March 2014 Accepted: 24 June 2014

Published online: 08 July 2014

\section{References}

1. Onat A, Hergenc G, Yuksel H, Can G, Ayhan E, Kaya Z, Dursunoglu D: Neck circumference as a measure of central obesity: associations with metabolic syndrome and obstructive sleep apnea syndrome beyond waist circumference. Clin Nutr (Edinburgh, Scotland) 2009, 28(1):46-51.

2. Yang L, Samarasinghe YP, Kane P, Amiel SA, Aylwin SJ: Visceral adiposity is closely correlated with neck circumference and represents a significant indicator of insulin resistance in WHO grade III obesity. Clin Endocrinol (Oxf) 2010, 73(2):197-200.

3. Liang J, Teng F, Li Y, Liu X, Zou C, Wang Y, Li H, Qi L: Neck circumference and insulin resistance in chinese adults: the cardiometabolic risk in Chinese (CRC) Study. Diabetes Care 2013, 36(9):e145-146.

4. Chagas P, Caramori P, Barcellos C, Galdino TP, Gomes I, Schwanke CH: Association of different anthropometric measures and indices with coronary atherosclerotic burden. Arq Bras Cardiol 2011, 97(5):397-401.

5. Dahlen EM, Bjarnegard N, Lanne T, Nystrom FH, Ostgren CJ: Sagittal abdominal diameter is a more independent measure compared with waist circumference to predict arterial stiffness in subjects with type 2 diabetes-a prospective observational cohort study. Cardiovasc Diabetol 2013, 12:55.

6. Mancia G, De Backer G, Dominiczak A, Cifkova R, Fagard R, Germano G, Grassi G, Heagerty AM, Kjeldsen SE, Laurent S, Narkiewicz K, Ruilope L, Rynkiewicz A, Schmieder RE, Boudier HA, Zanchetti A, ESH-ESC Task Force on the Management of Arterial Hypertension: 2007 ESH-ESC practice guidelines for the management of arterial hypertension: ESH-ESC Task Force on the management of arterial hypertension. J Hypertens 2007, 25(9):1751-1762.

7. Sutton-Tyrrell K, Najjar SS, Boudreau RM, Venkitachalam L, Kupelian V, Simonsick EM, Havlik R, Lakatta EG, Spurgeon H, Kritchevsky S, Pahor M, Bauer D, Newman A, Health ABC Study: Elevated aortic pulse wave velocity, a marker of arterial stiffness, predicts cardiovascular events in well-functioning older adults. Circulation 2005, 111(25):3384-3390.

8. Krantz MJ, Long CS, Hosokawa P, Karimkahani E, Dickinson M, Estacio RO, Masoudi FA, Havranek EP: Pulse wave velocity and carotid atherosclerosis in white and Latino patients with hypertension. BMC Cardiovasc Disord 2011, 11:15.

9. Protopsaltis I, Foussas S, Angelidi A, Gritzapis A, Sergentanis T, Matsagos S, Tzirogiannis K, Panoutsopoulos Gl, Dimitriadis G, Raptis S, Melidonis A: Impact of ADMA, endothelial progenitor cells and traditional cardiovascular risk factors on pulse wave velocity among prediabetic individuals. Cardiovasc Diabetol 2012, 11:141.

10. Naka KK, Papathanassiou K, Bechlioulis A, Kazakos N, Pappas K, Tigas S, Makriyiannis D, Tsatsoulis A, Michalis LK: Determinants of vascular function in patients with type 2 diabetes. Cardiovasc Diabetol 2012, 11:127.

11. Laurent S, Cockcroft J, Van Bortel L, Boutouyrie P, Giannattasio C, Hayoz D, Pannier B, Vlachopoulos C, Wilkinson I, Struijker-Boudier H: Expert consensus document on arterial stiffness: methodological issues and clinical applications. Eur Heart J 2006, 27(21):2588-2605.

12. Bia D, Zocalo Y, Armentano R, Laza S, Perez H, Craiem D, Saldias M, Alvarez I: Non-invasive biomechanical evaluation of implanted human cryopreserved arterial homografts: comparison with pre-implanted cryografts and arteries from human donors and recipients. Ann Biomed Eng 2009, 37(7):1273-1286.

13. O'Rourke MF, Pauca A, Jiang XJ: Pulse wave analysis. Br J Clin Pharmaco/ 2001, 51(6):507-522.

14. Hayward CS, Kraidly M, Webb CM, Collins P: Assessment of endothelial function using peripheral waveform analysis: a clinical application. J Am Coll Cardiol 2002, 40(3):521-528.
15. Liang J, Xue Y, Zou C, Zhang T, Song H, Qi L: Serum uric acid and prehypertension among Chinese adults. J Hypertens 2009, 27(9):1761-1765.

16. Teng F, Zhu R, Zou C, Xue Y, Yang M, Song H, Liang J: Interaction between serum uric acid and triglycerides in relation to blood pressure. $J$ Hum Hypertens 2011, 25(11):686-691.

17. Liang J, Zhou N, Teng F, Zou C, Xue Y, Yang M, Song H, Qi L: Hemoglobin A1c levels and aortic arterial stiffness: the cardiometabolic risk in Chinese (CRC) study. PLoS One 2012, 7(8):e38485.

18. Liang J, Li Y, Zhou N, Teng F, Zhao J, Zou C, Qi L: Synergistic effects of serum uric acid and cardiometabolic risk factors on early stage atherosclerosis: the cardiometabolic risk in Chinese study. PLoS One 2012, 7(12):e51101.

19. Expert Panel on Detection, Evaluation, and Treatment of High Blood Cholesterol in Adults: Executive Summary of The Third Report of The National Cholesterol Education Program (NCEP) Expert Panel on Detection, Evaluation, And Treatment of High Blood Cholesterol In Adults (Adult Treatment Panel III). JAMA 2001, 285(19):2486-2497.

20. Vlachopoulos C, Aznaouridis K, Stefanadis C: Prediction of cardiovascular events and all-cause mortality with arterial stiffness: a systematic review and meta-analysis. J Am Coll Cardiol 2010, 55(13):1318-1327.

21. Cavalcante JL, Lima JA, Redheuil A, Al-Mallah MH: Aortic stiffness: current understanding and future directions. J Am Coll Cardio/ 2011, 57(14):1511-1522.

22. Hughes TM, Althouse AD, Niemczyk NA, Hawkins MS, Kuipers AL, Sutton-Tyrrell K: Effects of weight loss and insulin reduction on arterial stiffness in the SAVE trial. Cardiovasc Diabetol 2012, 11:114.

23. Reference Values for Arterial Stiffness' Collaboration: Determinants of pulse wave velocity in healthy people and in the presence of cardiovascular risk factors: 'establishing normal and reference values'. European heart journal 2010, 31(19):2338-2350.

24. Safar ME, Levy Bl, Struijker-Boudier H: Current perspectives on arterial stiffness and pulse pressure in hypertension and cardiovascular diseases. Circulation 2003, 107(22):2864-2869.

25. Cruickshank K, Riste L, Anderson SG, Wright JS, Dunn G, Gosling RG: Aortic pulse-wave velocity and its relationship to mortality in diabetes and glucose intolerance: an integrated index of vascular function? Circulation 2002, 106(16):2085-2090.

26. Won KB, Chang HJ, Kim HC, Jeon K, Lee H, Shin S, Cho IJ, Park SH, Lee SH, Jang $Y$ : Differential impact of metabolic syndrome on subclinical atherosclerosis according to the presence of diabetes. Cardiovasc Diabetol 2013, 12:41.

27. Scuteri A, Cunha PG, Rosei EA, Badariere J, Bekaert S, Cockcroft JR, Cotter J, Cucca F, De Buyzere ML, De Meyer T, Ferrucci L, Franco O, Gale N, Gillebert TC, Hofman A, Langlois M, Laucevicius A, Laurent S, Mattace Raso FU, Morrell CH, Muiesan ML, Munnery MM, Navickas R, Oliveira P, Orru' M, Pilia MG, Rietzschel ER, Ryliskyte L, Salvetti M, Schlessinger D, et al: Arterial stiffness and influences of the metabolic syndrome: a cross-countries study. Atherosclerosis 2014, 233(2):654-660.

28. Hwang IC, Suh SY, Seo AR, Ahn HY, Yim E: Association between metabolic components and subclinical atherosclerosis in Korean adults. Korean $J$ Fam Med 2012, 33(4):229-236.

29. Lau KK, Wong YK, Chan YH, Yiu KH, Teo KC, Li LS, Ho SL, Chan KH, Siu CW, Tse HF: Prognostic implications of surrogate markers of atherosclerosis in low to intermediate risk patients with type 2 diabetes. Cardiovasc Diabetol 2012, 11:101.

30. Fitch KV, Stanley TL, Looby SE, Rope AM, Grinspoon SK: Relationship between neck circumference and cardiometabolic parameters in HIV-infected and non-HIV-infected adults. Diabetes Care 2011, 34(4):1026-1031.

31. Zhou JY, Ge H, Zhu MF, Wang U, Chen L, Tan YZ, Chen YM, Zhu HL: Neck circumference as an independent predictive contributor to cardio-metabolic syndrome. Cardiovasc Diabetol 2013, 12:76

32. Nielsen S, Guo Z, Johnson CM, Hensrud DD, Jensen MD: Splanchnic lipolysis in human obesity. J Clin Invest 2004, 113(11):1582-1588.

33. Stojiljkovic MP, Lopes HF, Zhang D, Morrow JD, Goodfriend TL, Egan BM: Increasing plasma fatty acids elevates $\mathrm{F} 2$-isoprostanes in humans: implications for the cardiovascular risk factor cluster. J Hypertens 2002, 20(6):1215-1221.

34. Piro S, Spampinato D, Spadaro L, Oliveri CE, Purrello F, Rabuazzo AM: Direct apoptotic effects of free fatty acids on human endothelial cells. Nutr Metab Cardiovasc Dis 2008, 18(2):96-104. 
35. Steiropoulos P, Bogiatzi C, Archontogeorgis K, Nena E, Xanthoudaki M, Boglou P, Tzouvelekis A, Papanas N, Tsivgoulis G, Bouros D: Is there evidence of early vascular disease in patients with obstructive sleep apnoea without known comorbidities? Preliminary findings. Open Cardiovasc Med J 2013, 7:61-68.

36. Apaydin M, Ayik SO, Akhan G, Peker S, Uluc E: Carotid intima-media thickness increase in patients with habitual simple snoring and obstructive sleep apnea syndrome is associated with metabolic syndrome. J Clin Ultrasound 2013, 41(5):290-296.

37. Laakso M, Matilainen V, Keinanen-Kiukaanniemi S: Association of neck circumference with insulin resistance-related factors. Int I Obes Relat Metab Disord 2002, 26(6):873-875.

38. Tsioufis C, Dimitriadis K, Selima M, Thomopoulos C, Mihas C, Skiadas I, Tousoulis D, Stefanadis C, Kallikazaros I: Low-grade inflammation and hypoadiponectinaemia have an additive detrimental effect on aortic stiffness in essential hypertensive patients. Eur Heart J 2007, 28(9):1162-1169.

39. O'Leary DH, Polak JF: Intima-media thickness: a tool for atherosclerosis imaging and event prediction. Am J Cardiol 2002, 90(10C):18L-21L.

40. Klein S, Hage JJ: Measurement, calculation, and normal range of the ankle-arm index: a bibliometric analysis and recommendation for standardization. Ann Vasc Surg 2006, 20(2):282-292.

doi:10.1186/s12933-014-0107-x

Cite this article as: Liang et al:: Neck circumference and early stage atherosclerosis: the cardiometabolic risk in Chinese (CRC) study. Cardiovascular Diabetology 2014 13:107.

\section{Submit your next manuscript to BioMed Central and take full advantage of:}

- Convenient online submission

- Thorough peer review

- No space constraints or color figure charges

- Immediate publication on acceptance

- Inclusion in PubMed, CAS, Scopus and Google Scholar

- Research which is freely available for redistribution 